University of Nebraska - Lincoln

DigitalCommons@University of Nebraska - Lincoln

Publications, Agencies and Staff of the U.S.

Department of Commerce

U.S. Department of Commerce

2012

\title{
A pollen-based reconstruction of summer temperature in central North America and implications for circulation patterns during medieval times
}

\author{
Eugene R. Wahl \\ NOAA/NCDC/Paleoclimatology, Eugene.R.Wahl@noaa.gov \\ Henry F. Diaz \\ NOAA/CIRES \\ Christian Ohlwein \\ University of Bonn
}

Follow this and additional works at: https://digitalcommons.unl.edu/usdeptcommercepub

Part of the Environmental Sciences Commons

Wahl, Eugene R.; Diaz, Henry F.; and Ohlwein, Christian, "A pollen-based reconstruction of summer temperature in central North America and implications for circulation patterns during medieval times" (2012). Publications, Agencies and Staff of the U.S. Department of Commerce. 358.

https://digitalcommons.unl.edu/usdeptcommercepub/358

This Article is brought to you for free and open access by the U.S. Department of Commerce at DigitalCommons@University of Nebraska - Lincoln. It has been accepted for inclusion in Publications, Agencies and Staff of the U.S. Department of Commerce by an authorized administrator of DigitalCommons@University of Nebraska - Lincoln. 


\title{
A pollen-based reconstruction of summer temperature in central North America and implications for circulation patterns during medieval times
}

\author{
Eugene R. Wahl ${ }^{\mathrm{a}, *}$, Henry F. Diaz ${ }^{\mathrm{b}}$, Christian Ohlwein ${ }^{\mathrm{c}}$ \\ a NOAA/NCDC/Paleoclimatology, 325 Broadway, Boulder, CO USA \\ ${ }^{\mathrm{b}}$ NOAA/CIRES, 325 Broadway, Boulder, CO, USA \\ c Meteorological Institute, University of Bonn, 53121 Bonn, Germany
}

\section{A R T I C L E I N F O}

\section{Article history:}

Received 8 June 2011

Received in revised form 28 September 2011

Accepted 8 October 2011

Available online 17 October 2011

\section{Keywords:}

medieval climate anomaly

temperature reconstruction

paleoclimate

NAO

Wisconsin

pollen

\begin{abstract}
A B S T R A C T
We present a reconstruction of mean summer temperature for the northern Midwest of the USA based on lacustrine pollen records from three different lakes in Wisconsin. The results suggest a relatively warm period during the earlier part of the record $(\sim 1200-1500$ CE) followed by a cooler Little Ice Age $(\sim 1500-1900)$ and a subsequent warming to modern conditions. The reconstructed modern summer mean temperature is in good agreement with observations, and the decades of the 1930s to 1950s appear to be the warmest such period in the proxy record (through 1974).

Analyses of circulation features associated with the warmest summers in the recent climate record suggest a prevalence of continental ridging accompanied by generally dry conditions during these warm summers in the Midwest. Drought reconstruction using the Palmer Drought Severity Index (PDSI) and tree-ring records as predictors also yield relatively dry conditions in medieval times for the central US. As reported in a number of recent studies, possible forcing mechanisms include La Niña-like conditions in the equatorial Pacific and warmer than average waters in the tropical Indo-western Pacific Ocean possibly coupled to a positive mode of the AMO/ NAO North Atlantic circulation pattern.
\end{abstract}

Published by Elsevier B.V.

\section{Introduction}

Many aspects of the climate prevailing during the so-called Medieval Climate Anomaly (MCA) in the western United States have been well documented (e.g., La Marche, 1974; Hughes and Brown, 1992; Graumlich, 1993; Dean, 1994; Stine, 1994; Cook et al., 2004; Salzer and Kipfmueller, 2005; Graham and Hughes, 2007), while a number of modeling studies have endeavored to provide possible mechanistic explanations for the occurrence of reconstructed climate patterns during this time (Graham et al., 2007, 2010; Seager et al., 2007). Comparatively fewer paleoclimatic studies focused on the eastern United States have been published for the nominal period of the MCA ( 900-1400 CE). Some representative studies covering this period include inter alia Booth et al. (2006), Stahle et al. (2007), and Shuman et al. (2009). Studies focused on the western prairies and Great Plains region to the west of our study area have inferred periods of aridity with sand dune mobilization and contraction of lakes for portions of the MCA (Laird et al., 2003; Mason et al., 2004).

Recently, a number of modeling studies that have incorporated the latest information on boundary conditions for parts of the last 500-1000 years (Graham et al., 2007, 2010; Seager et al., 2007) have demonstrated strong connectivity of multi-decadal hydrologic anomalies in North America to both the Indo-Pacific and Atlantic Oceans regions.

\footnotetext{
* Corresponding author. Tel.: +13034976297.

E-mail address: Eugene.R.Wahl@noaa.gov (E.R. Wahl).
}

Inferred circulation patterns from these studies suggest that the tropical Indo-Pacific was La Niña-like (i.e., with relatively cool waters in the eastern equatorial Pacific and warmer than normal waters in the western tropical Pacific and Indian Ocean) as well as a warm North Atlantic with strengthened subtropical high pressure.

Here we present a new approach to reconstructing summer (JuneJuly-August, JJA) temperature in the northern Midwest of the USA for the last 1000 years using pollen records from three lakes in the state of Wisconsin. We also examine the possibility that circulation patterns associated with some recent extreme summers may be indicative of circulation patterns prevalent during the MCA and discuss their suitability as MCA circulation analogs.

\section{Data and methods}

Implementation of a new version of the pollen ratio method of temperature reconstruction (cf. Adam and West, 1983) is introduced. This new approach uses an optimized selection of pollen taxa in the binomial logistic form of the generalized linear model (GLM) to estimate a pollen-climate forward relationship based on modern pollen and associated climate data in temperate northeastern North America. [The methodology used is described in Wahl et al.(2010) and the included supplementary online material (SOM), and in Ohlwein and Wahl (accepted for publication); see also Whitmore et al.(2005) for the modern pollen data and associated bio-climatic information.] The 
GLM model was estimated using both classical and Bayesian inference methods in the $\mathrm{R}$ language ( $\mathrm{R}$ Foundation for Statistical Computing). This forward relationship was then inverted to yield expected value
(EV) reconstructions of summer temperature, based on fossil pollen assemblages. Explicit modeling of reconstruction uncertainty was done in the inverted form using a 2-way Monte Carlo framework, based on the
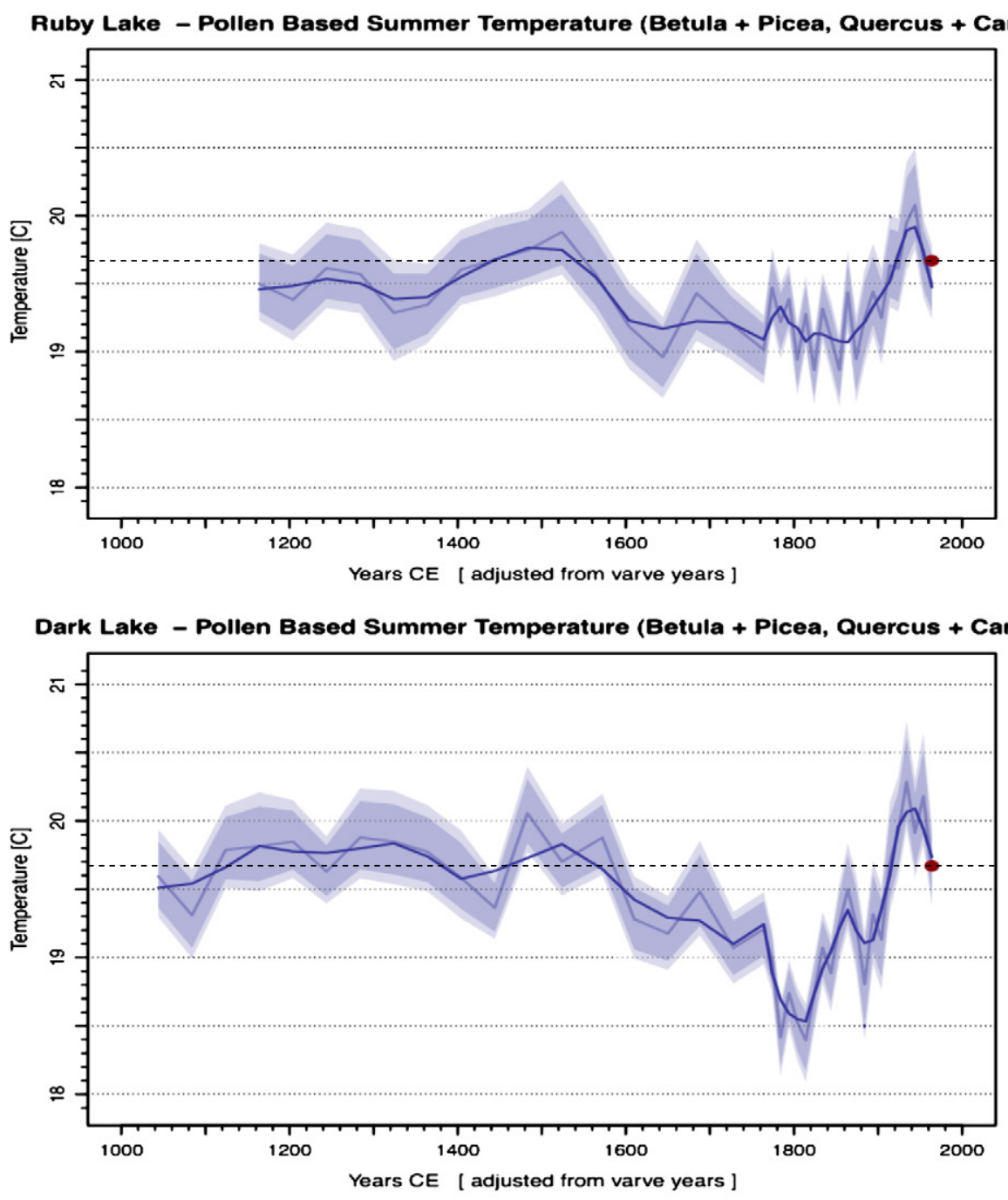

Little Pine Lake - Pollen Based Summer Temperature (Betula + Picea, Quercus + Carya)

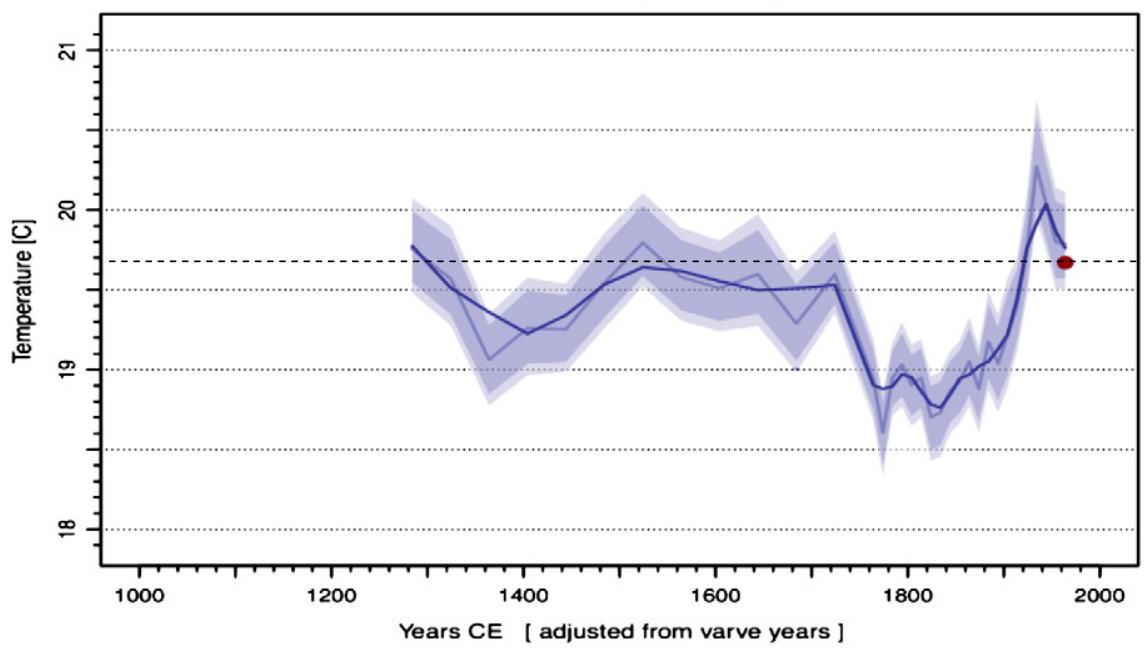

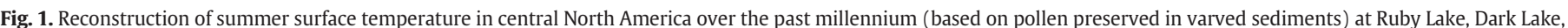

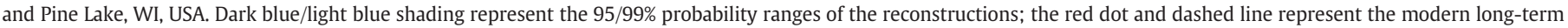

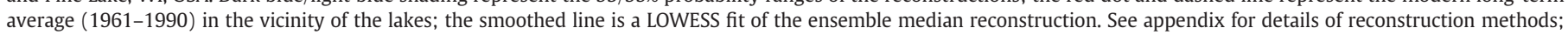
results from the Bayesian version of the statistical model are shown. 


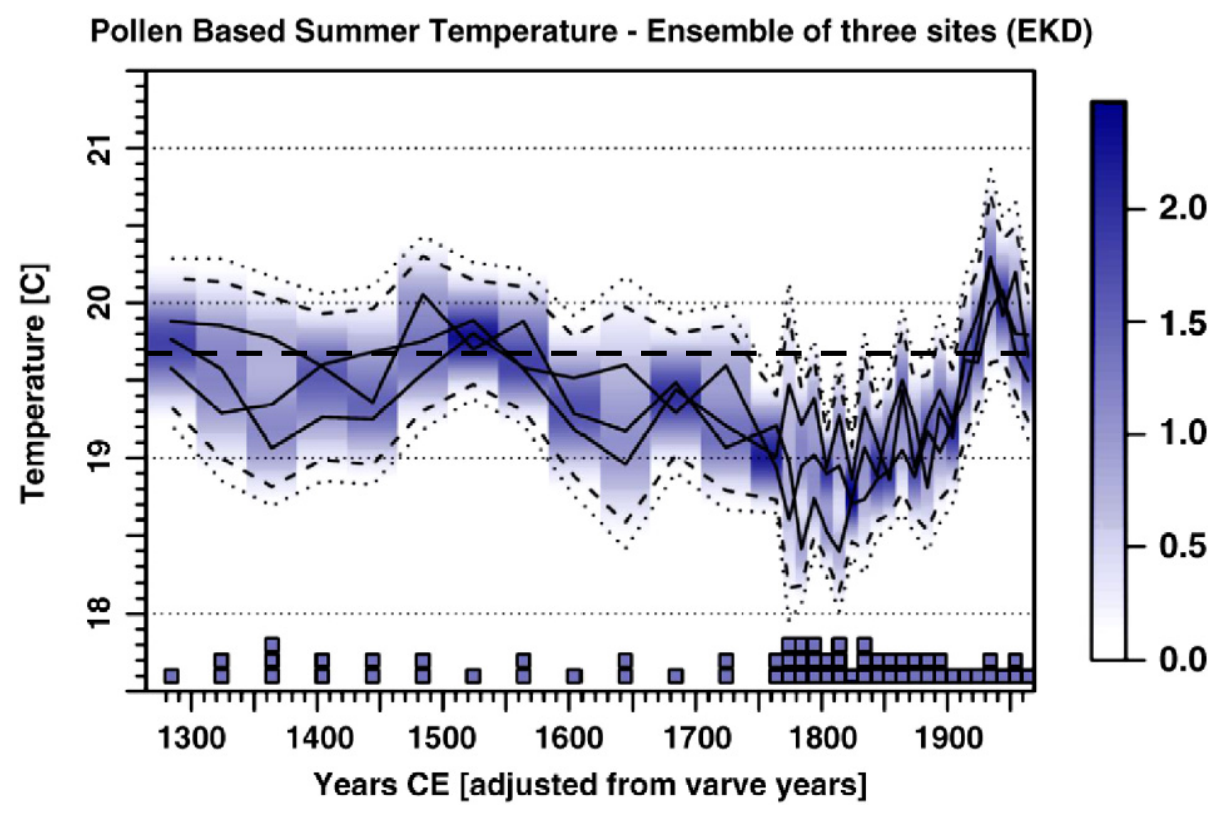

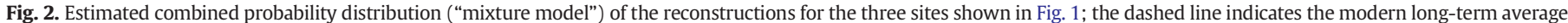

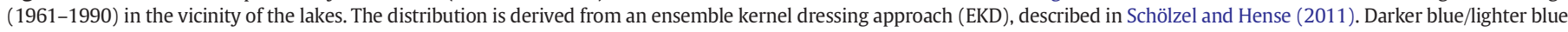

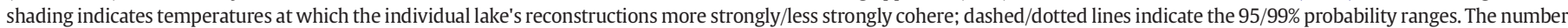

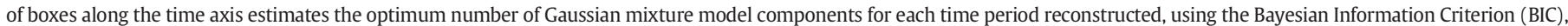

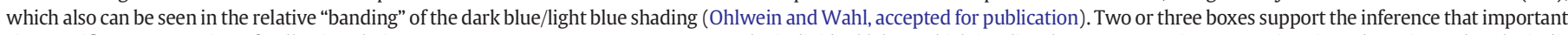

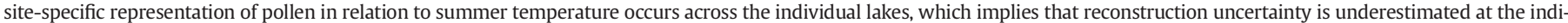
vidual sites and leads to wider estimated probability ranges in the mixture model.

binomial specification of the ratio model and the estimated distributions of the GLM parameters (assuming normality for the classically-estimated model and using the joint posterior distribution in the Bayesian model). Additional information on the GLM ratio model is provided in the Appen$\operatorname{dix} \mathrm{A}$.

We used sea level pressure and $700 \mathrm{mb}$ geopotential height data from the NCEP/NCAR reanalysis (Kistler et al., 2001) to consider possible circulation analogs for the MCA in North America. Instrumental temperatures used for this analysis were based on the HadCRUT3v data set

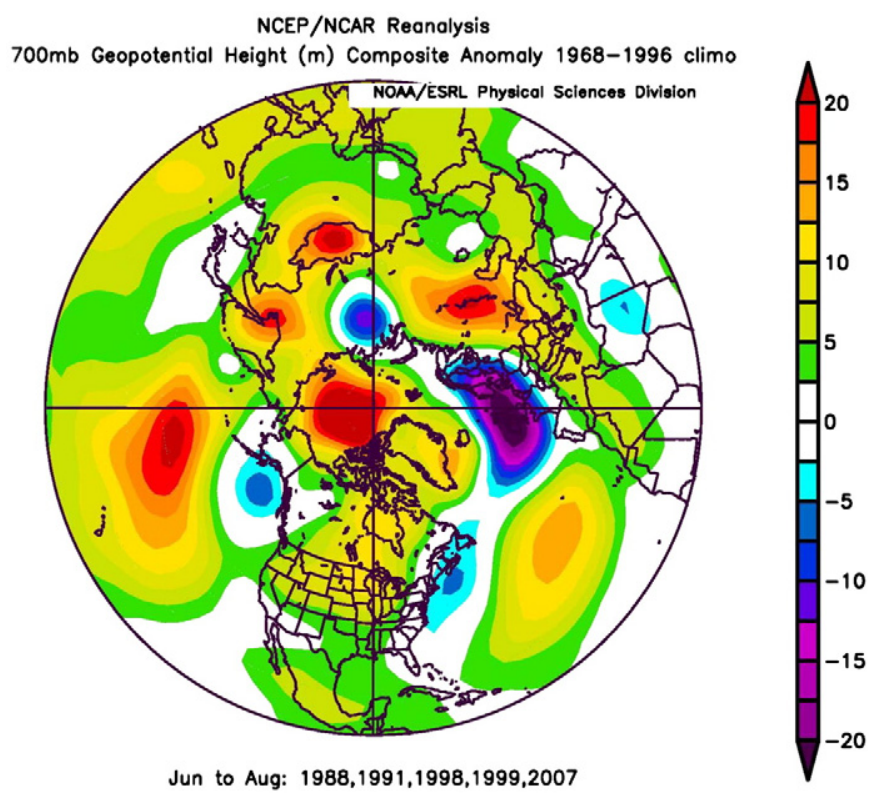

Fig. 3. Seven hundred mb geopotential height composite anomaly for JJA 1988, 1991, 1998,1999 , and 2007. The composite shows a distinct positive-phase NAO-type anomaly pattern over the North Atlantic.
(Brohan et al., 2006) for a square comprising the four $5^{\circ}$ grid cells approximately centered on the reconstruction area. For comparison purposes we also used a state-average temperature record for Wisconsin from the USA National Climatic Data Center (NCDC) archive to calculate average summer temperature for the period 1895-2010.

\section{Results and discussion}

\subsection{Paleoclimate inferences}

Validated summer temperature reconstructions for the northern Midwest of the United States (western central Wisconsin) were developed with the inverted GLM ratio method from three absolutely dated (varved) lake basins (Gajewski et al., 1985; cf. Gajewski, 1988); these are shown in Fig. 1, based on the Bayesian estimation of the GLM model. For these three basins, the modern summer temperature climatology values (1961-1990; from Whitmore et al.(2005)) are well inside the 95\% probability ranges of the inversion reconstructions, which constitutes a minimum validation test for the reconstruction methodology (cf. Fig. 1). Where also feasible (i.e., where both the numerator-specific taxa, Betula and Picea, and the denominator-specific taxa, Quercus and Carya, were present above trace levels so the model could be reasonably employed), the inverted GLM ratio model was also applied to other lake basins in temperate Northeastern North America with high resolution data coverage over the past millennium. In these other lakes, the modern climatology values are far outside the $99 \%$ probability ranges from the inversion reconstructions, and therefore this information was not considered validated and was not reliable for reconstruction use. Thus, the reconstructions examined here are limited to the northern Midwest region, from the western central Wisconsin sites. Similar region-specific reconstruction success/issues using an earlier generation of pollen-based regression models are discussed by Bartlein et al. (2010), cf. sec. 2.3 therein.

The high explained deviance of the GLM model (analogous to explained variation in a standard linear model) (Wahl et al., 2010, SOM) provides reconstructions with $99 \%$ probability ranges that are 
NCEP/NCAR Reanalysis

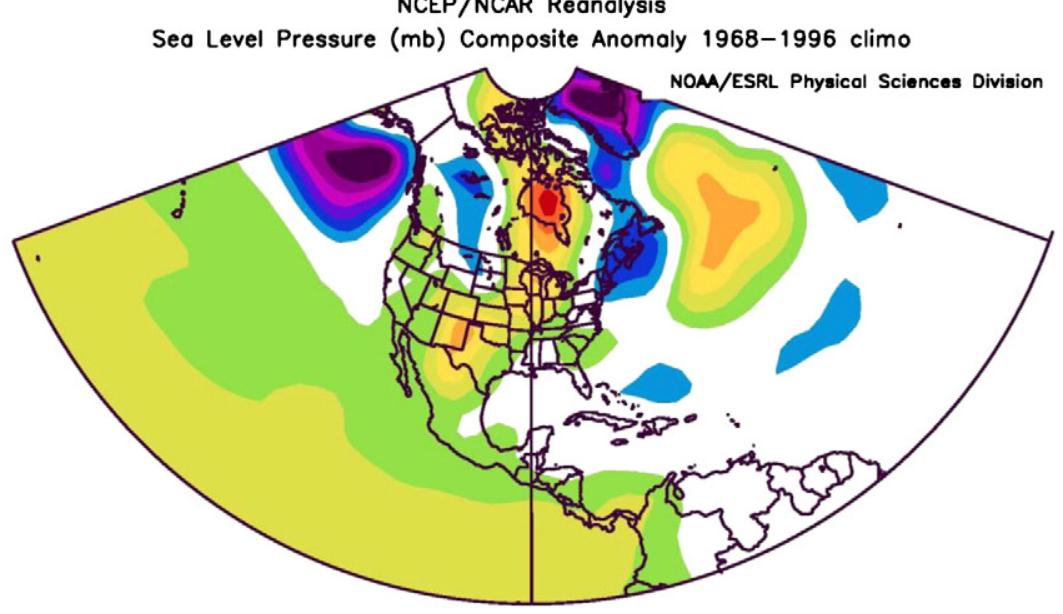

Jun to Jul: 1988

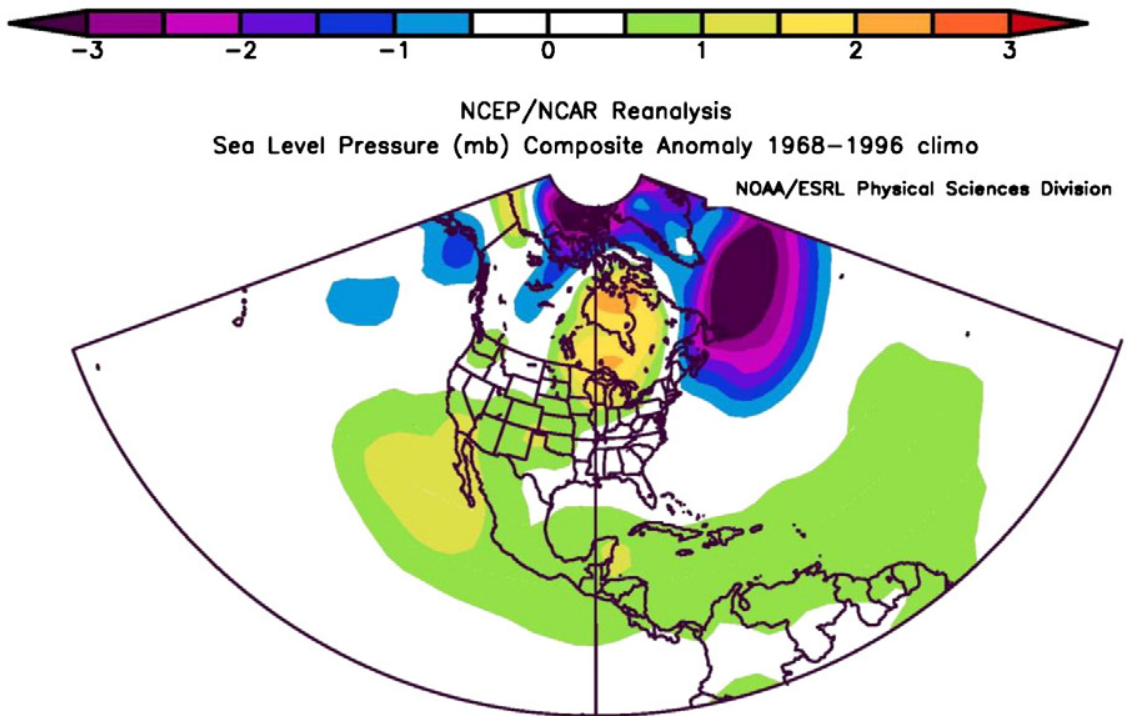

Jun to Aug: 1991

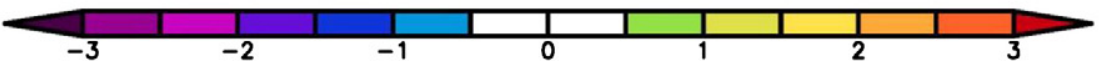

Fig. 4. Sea level pressure anomalies for the summers (JJA) of 1988 and 1991.

narrow enough to allow clear distinction of a cooler LIA in relation to earlier and later times (by $\sim 1.5{ }^{\circ} \mathrm{C}$ [somewhat less for Ruby Lake, Fig. 1], compared to a mean $99 \%$ reconstruction probability range $\left.\leq \pm 0.4{ }^{\circ} \mathrm{C}\right)$. The Bayesian median reconstructions are nearly identical to the EV reconstructions from the classical frequentist method, while the corresponding percentile probability ranges from the Bayesian reconstructions are somewhat narrower than those derived from the frequentist methods. The Bayesian median values and probability ranges are reported in Fig. 1.

The reconstructions from all three basins indicate a relatively late onset of the MCA-LIA transition, at approximately 1400-1450 CE, based on the assumption of a median 50-100 year lag in forest vegetation response to climate (cf. Williams et al.(2002); Webb (1986) estimates a similar lag in relation to LIA changes). However, known climatic features, such as the 1930s to 1940s warming and cooling associated with the Tambora and Krakatau volcanic explosions in the 19th century, are indicated in the pollen-based reconstruction from Dark Lake with timing nearly synchronous to the actual events
(Fig. 1); the former feature also clearly occurs in the Ruby and Little Pine Lakes reconstructions. These features suggest that the vegetation could have been responding essentially in real time in terms of pollen production to temperature variations (cf. Viau and Gajewski, 2009). If this is the case, then the inverted reconstructions would indicate a late 15 th-early 16 th century onset of the LIA in this region. Webb (1986) examines the effect of vegetation lagging climate on the amplitude of pollen-based climate reconstructions. These findings indicate that a lag 1/20 the length of the relevant climate event has little effect on amplitude, whereas a lag equal to the length of the climate event will profoundly impact amplitude. The evidence from Dark Lake, and for the early 20th century from all three lakes, suggests that any lag effect involved in the reconstructions reported here is likely to be less than 40 years in length (perhaps much less), and thus less than $1 / 10$ the length of the LIA, which would indicate that amplitude loss, if present, is likely to be small. The overall interpretation based on the individual reconstructions remains essentially unchanged when ensemble post-processing methods (Schölzel and 


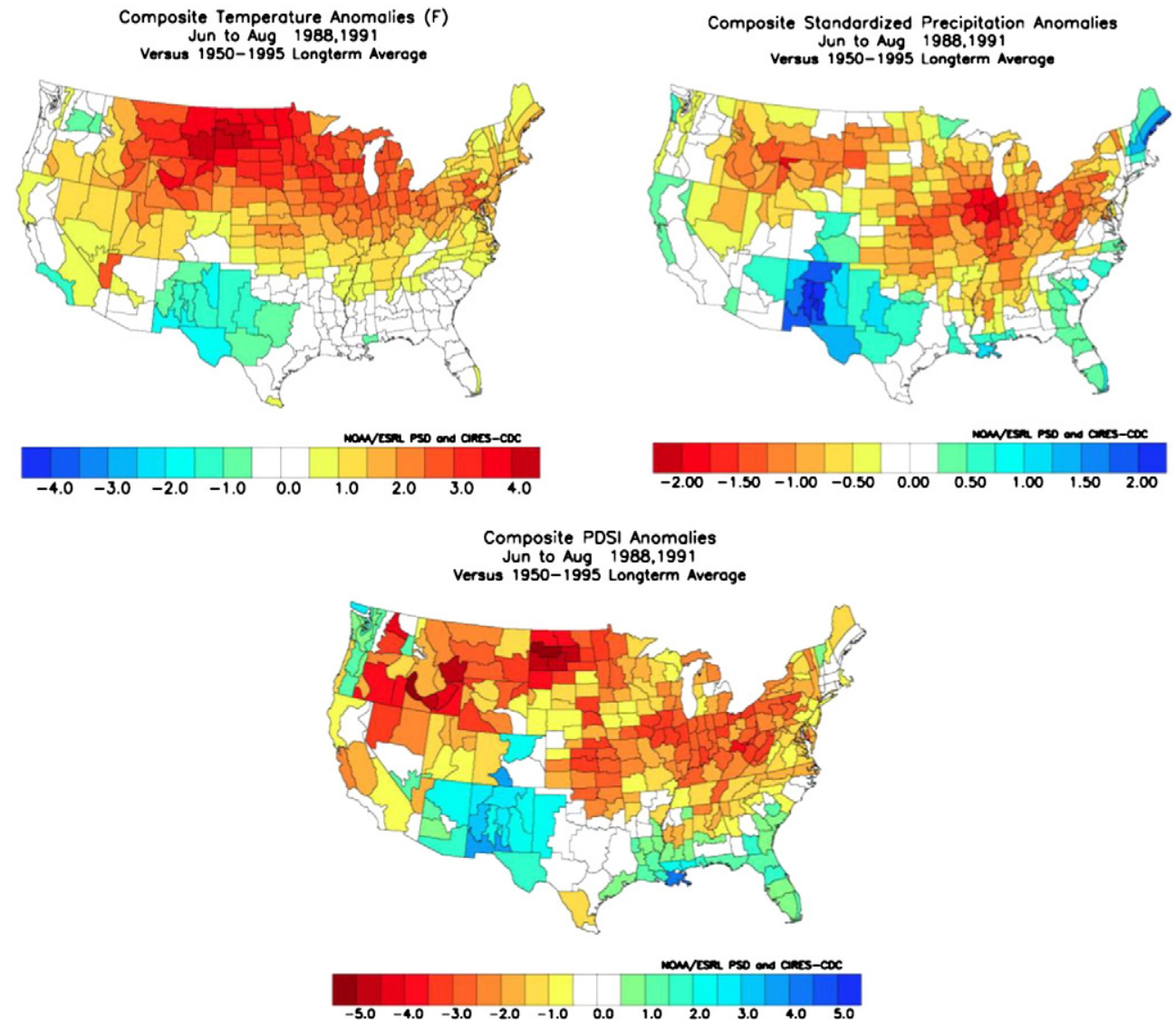

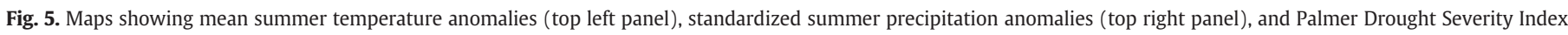
(bottom panel) in the USA for the years 1988 and 1991.

\section{Reconstructed PDSI CE 1120-1200}

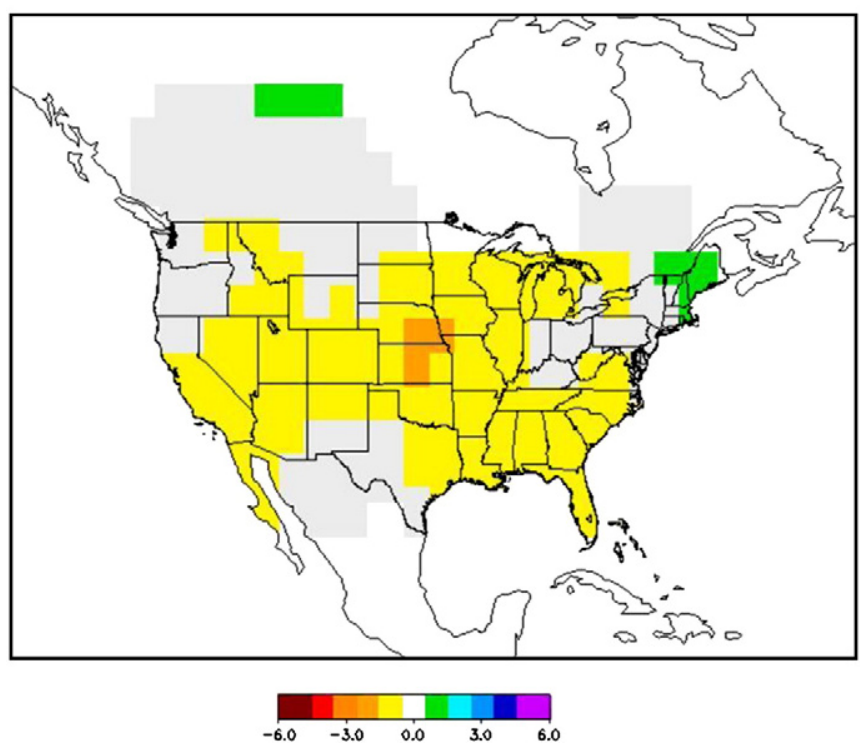

Fig. 6. Reconstructed PDSI for the period CE 1120-1200 during the MCA interval with mid-summer temperature reconstruction at Dark Lake (our longest pollen record) indicating relative warm summers in the northern Midwest of the USA. Data are from Cook et al. (2004), as updated in 2008, at NOAA's National Climatic Data Center Paleoclimate Branch/World Data Center for Paleoclimatology (http://www.ncdc. noaa.gov/cgi-bin/paleo/pd08plot.pl).
Hense, 2011) are used to combine the estimated probability distributions of the individual lakes (Fig. 2); note that the most likely excursion of LIA cooling reduces to $\sim 1.0^{\circ} \mathrm{C}$ and the width of the overall $99 \%$ probability range expands to $\leq \pm 1.05^{\circ} \mathrm{C}$ (generally $\leq \pm 0.8^{\circ} \mathrm{C}$ ).

Summer temperature reconstructions for the same three lakes were reported by Gajewski (1988). These reconstructions have generally similar time trajectories over the past millennium to those reported in Figs. 1 and 2 here, with somewhat less cooling during the LIA, and without accompanying estimation of uncertainty ranges. Detailed comparison of the Gajewski (1988) reconstructions with those reported here is provided in the Appendix A.

\subsection{Connection to the larger-scale circulation}

Using the $700 \mathrm{mb}$ geopotential height field as input, simple composite patterns were produced as possible modern analog fields for those periods during the MCA with temperatures that are reconstructed near modern values. This analog analysis is based on the simple assumption that pressure patterns associated with modern anomalously warm summer conditions in the reconstruction region may have been similar to those that occurred during the prior warmest times in these records-the MCA period (Fig. 1, cf. Diaz and Andrews, 1982). We composited the $700 \mathrm{mb}$ Northern Hemisphere geopotential height anomalies for the warmest 10 years of modern (post-1958) JJA temperatures in the reconstruction region. One-half of the modern regional warmest summers are associated with a composite pressure anomaly pattern that is quite similar to a positive phase of the North Atlantic Oscillation (NAO) (Figs. 3 and 4). The other half of the modern warmest summers is associated with a variety of other circulation configurations, including some negative NAO-like patterns. This variation of summer 


\section{Seasonal Temperature / Precipitation Relationship \\ OBSERVED}

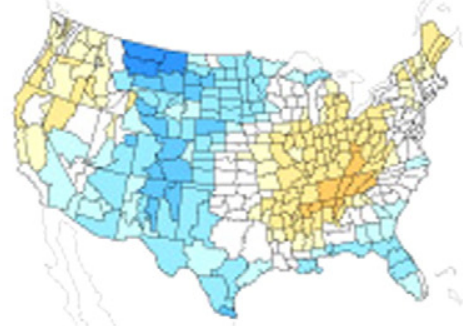

DJF

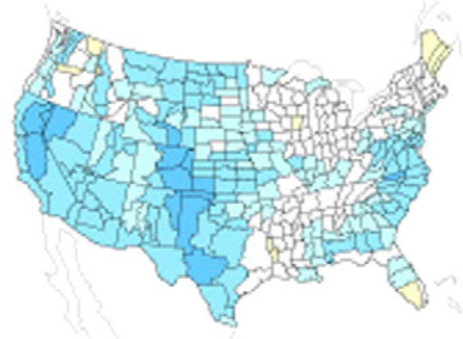

MAM

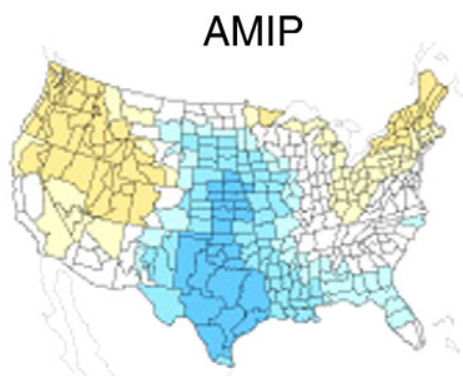

JJA
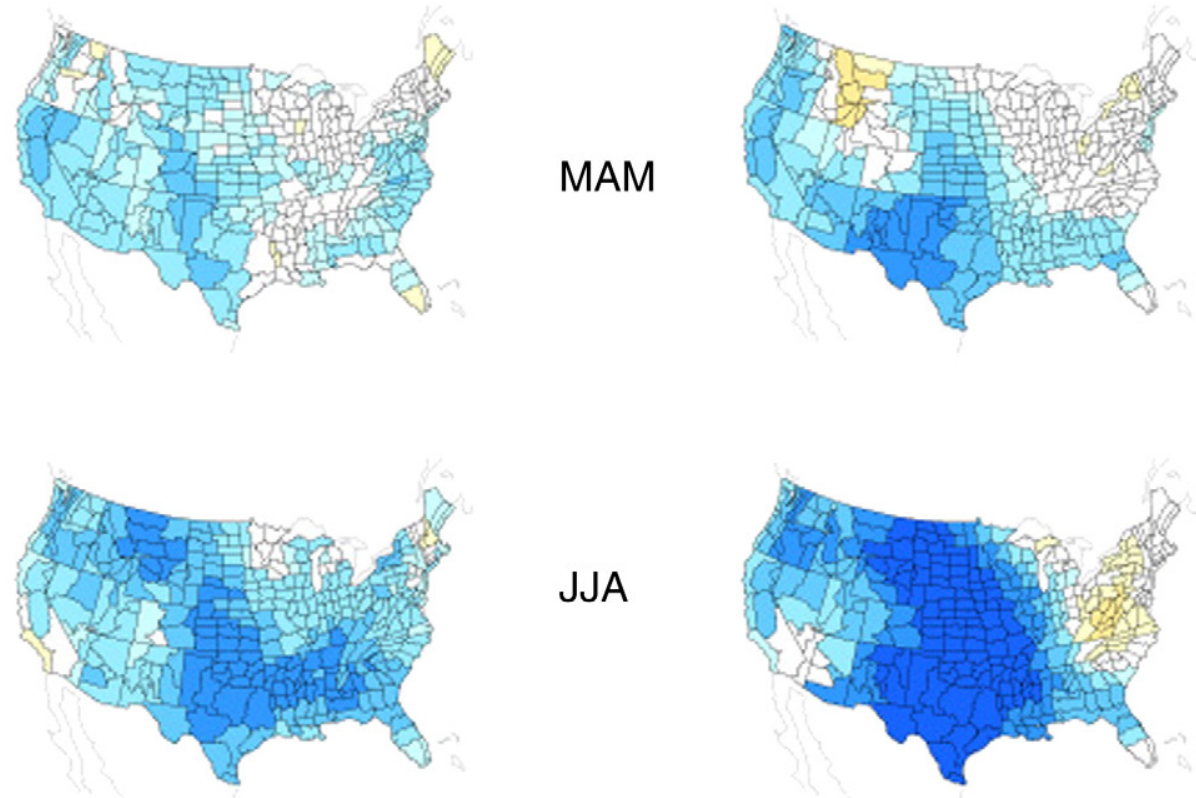

SON
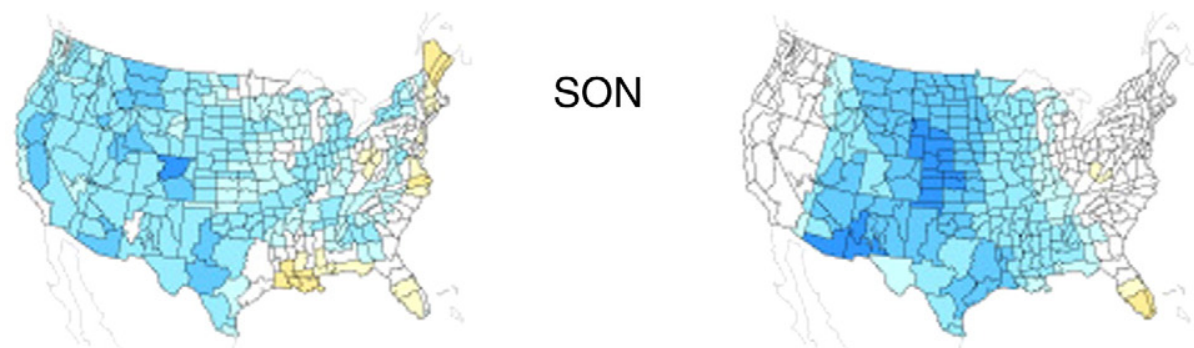

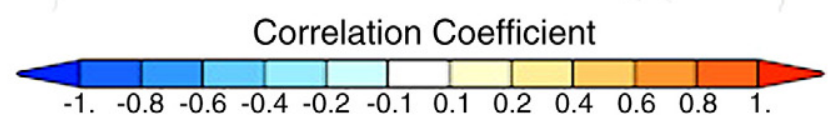

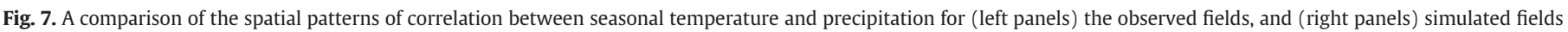
(see text). Graph courtesy of Jon Eischeid (NOAA/ESRL-CIRES).

circulation pattern configurations is also indicated by Fereday et al. (2008); see also McCabe et al. (2004).

More generally, using a sophisticated cluster analysis methodology, Fereday et al. (2008) have linked such modern pressure anomaly patterns with La Niña-like conditions in the equatorial Pacific (cf. Fig. 7 therein). Taken together, the modern analog and cluster analyses suggest that the MCA may have exhibited a tendency during summer to exhibit positive NAO and La Niña-like conditions. Such a tendency is similar to recent interpretations by Trouet et al. (2009) and (together with slight warming of the tropical Indian and western Pacific Oceans) by Graham et al. (2010) for MCA winter conditions.

In addition, the patterns shown in Figs. 3 and 4 are notable for the following. Besides indication of the presence of anomalously strong subtropical high pressure in the North Atlantic, surface pressures are also relatively high in the tropical Pacific during 1988 and 1991, in association with La Niña conditions. Higher than normal pressures, above normal temperatures and drought in interior North America were also associated with these two potential analog years (Figs. 4 and 5). Trouet 
et al. (2009) and Graham et al. (2010) suggest that prevalence for anomalous ridging in interior North America during the MCA, if correct, would also likely have been associated with Midwestern drought. ${ }^{1}$ Fig. 6 shows the spatial distribution of mean PDSI values reconstructed from tree-ring records (Cook et al., 2004, 2007) for the period 1120-1200 $\mathrm{CE}$, reconstructed as the driest period in the last millennium in the northern Midwest, which supports this conclusion. Although these interpretations form a coherent climatological picture, it is important to caution that simple constructs related to idealized pictures of prevailing circulation patterns likely comprise only one among a number of other factors contributing to the inferred mean summer climate in this region (cf. Shinker et al., 2006).

\section{Discussion and summary}

A reconstruction of summer temperature from pollen records extracted from several lakes in the northern Midwest is presented for much of the last 1000 years. A relatively warm MCA $(\sim 1100-1500)$ and cool Little Ice Age $(\sim 1500-1900)$ are reconstructed using a generalized linear model calibrated against modern summer temperature employing both classical and Bayesian inference methods. We consider plausible circulation "analogs" using surface and upper air composites that may have been more prevalent during the earlier compared to the later period. These "analog" patterns are shown to be consistent with circulation patterns simulated by general circulation models using generalized sea surface temperature patterns consistent with La Niña-like conditions in the tropical Indo-Pacific Ocean region. Independent reconstructions of North Atlantic circulation patterns reminiscent of positive NAO/AMO conditions are also consistent with those presented here.

While effective moisture changes are not reconstructed here, the climatic patterns that generally lead to warmer summers in the region where the lake pollen records were derived are more broadly associated with anomalous high-pressure and continental scale drought (Figs. 3-6). Furthermore, a comparison of maps of observed correlations between seasonal temperature and precipitation for the contiguous USA with those produced by AMIP simulations (forced by observed global SSTs) is consistent in showing a tendency for large scale moisture deficits in association with warmer than average temperatures (Fig. 7).

In summary, in contrast to a colder period evident from about CE 1600-1900 the early part of the reconstructed summer temperatures is comparable to the 20th century in the region of the northern Midwest of the USA. The decades of the 1930s to 1950s are the warmest period in the reconstruction record (ending in 1974 when the lake sediments were extracted), consistent with instrumental data from NCDC for the 20th century in Wisconsin (not shown), and somewhat higher than multi-decadal periods within the nominal MCA period.

\section{Appendix A}

\section{A.1. Detail on GLM pollen ratio model}

The GLM pollen ratio model used in this paper can be viewed as a refinement of the traditional pollen ratio method (cf. Adam and West, 1983). The ratio method has been known for some time to be a useful tool in pollen-based paleoclimate reconstruction, especially in situations in which one (or a few) dominant pollen type(s) in a region have a strong positive correlation with a climate variable of interest and another (or a few) dominant pollen type(s) have a strong negative correlation with the same climate variable. The binomial-logistic formulation of the generalized linear model (GLM) (Gelman et al., 2004) represents a new way to specify the ratio method, which provides a statistically, mathematically, and biophysically well-expressed structure

\footnotetext{
${ }^{1}$ The correlation between average summer temperature and total precipitation for Wisconsin in the modern record is $r=-0.14$ (not significant at the $10 \%$ level).
}

for the following reasons. First, the numerators of ratios formed from Poisson distributed pollen count data (for each taxon $P$ ) of the form $\Sigma P_{i} /\left(\Sigma P_{i}+\Sigma P_{j}\right)$ are binomially distributed, conditional on the pollen sum (across taxonomic groupings $i$ and $j$ ). [In terms of nomenclature, the taxonomic grouping $i$ can be called the "numerator-specific taxa" and taxonomic grouping $j$ can be called the "denominator-specific taxa", which are also binomially distributed conditional on the overall pollen sum.] Second, the logistic formulation of the modeled climateto-pollen relationship is both mathematically appropriate (the ratio values are constrained by construction to be limited to the range 0,1 ) and physically appropriate (i.e., it is a forward model, expressing the physically correct direction of causation).

For calibration, the modern data forward model is as follows:

$r_{\text {num }} \sim \operatorname{bin}(n, p)$, where

$E(r \mid C) \equiv p=\exp (\eta) /[1+\exp (\eta)]$ and $\eta=\alpha+\beta(C)$.

Here, $r$ is the pollen ratio defined in the prior paragraph, $\Sigma P_{i} /\left(\Sigma P_{i}+\right.$ $\left.\Sigma P_{j}\right) ; r_{\text {num }}$ is the ratio numerator, $\Sigma P_{i} ; n$ is the ratio denominator, $\Sigma P_{i}+$ $\Sigma P_{j}$; the denominator-specific count is $n-r_{\text {num }}, \Sigma P_{j}$; and $C$ is the climate value at each modern data site corresponding to a value of $r$. Once $\alpha$ and $\beta$ are estimated, which can be done using either Bayesian or classical GLM methods (Hadfield, 2010), climate reconstruction can be done by solving the GLM equations for $C$ as a function of $\alpha, \beta$, and $p$. This solution is

$C=\{\ln [p /(1-p)]-\alpha\} / \beta$.

It is important to note that the inversion solution is in terms of the modern values of the climate variable used to estimate the GLM, and not strictly in terms of paleo-values. To use this formula to reconstruct paleoclimate, the inversion model is re-expressed as follows: where the subscript "recon" denotes the reconstructed $C$ value, the subscript "est" denotes an estimate for a component of the reconstruction formula, and the subscript "fossil" denotes fossil pollen information.

$$
\begin{aligned}
C_{\text {recon }} & =\left\{\ln \left[p_{\text {est }} /\left(1-p_{\text {est }}\right)\right]-\alpha_{\text {est }}\right\} / \beta_{\text {est }}, \text { where } p_{\text {est }} \\
& =r_{\text {(fossil)est }} \equiv r_{\text {num(fossil)est }} / n_{\text {fossil }} .
\end{aligned}
$$

Here, the observed $r$ values from the fossil pollen data are assumed to be good estimators of the true fossil $r$ value at each time step sampled, and therefore can be substituted for $p$. Based on this assumption, the above formula yields the estimated expected values of reconstructed paleoclimate, given the observed fossil $r$ values and the estimated modal values for the GLM parameters $\alpha$ and $\beta$ (for Bayesian estimation) or estimated expected values of these parameters (for classical estimation). A 2-way Monte Carlo method for generating probability distribution envelopes around the modal/EV reconstructions employs random draws from the binomial distributions of the numerator- and denominator-specific pollen counts in the fossil $r$-values, in conjunction with random draws from the estimated distributions of $\alpha$ and $\beta$. Further statistical description and mathematical refinement related to this uncertainty ensemble generation process is provided in Ohlwein and Wahl (accepted for publication).

[Note that the mathematical refinement mentioned, which uses the fossil numerator- and denominator-specific counts as parameters in the Beta distribution to derive random draws for pest, is asymptotically equivalent to estimating random draws for pest as ratios formed from random binomial draws of the numerator- and denominator-specific fossil pollen counts, which is the method utilized here.] The numeratorspecific taxa used in here are Betula and Picea; the denominator-specific taxa are Quercus and Carya. Full description of determination of the taxa used in the model is provided in Wahl et al. (2010), cf. the supplementary online material, Section S1, first paragraph. 
Dark Lake Wisconsin, USA Pollen-Based JJA T
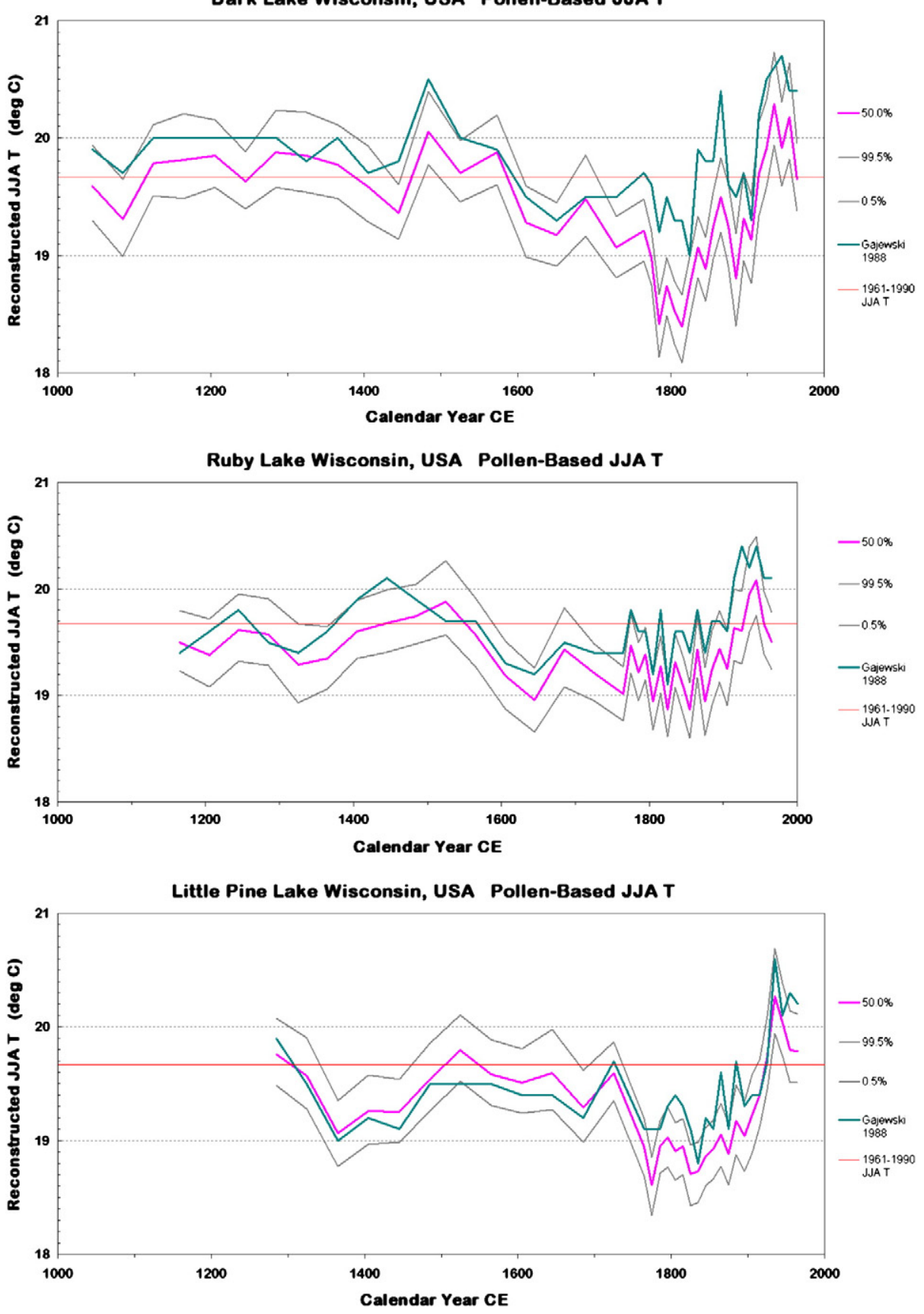

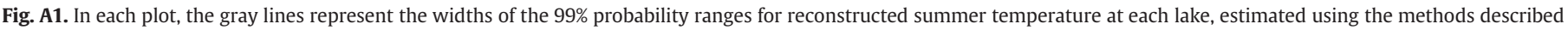

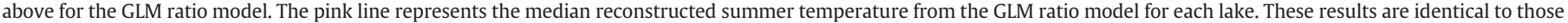

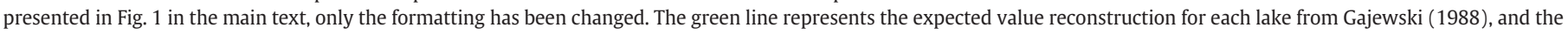
thin red line represents the 1961-1990 JJA climatology for the three-lake area from Whitmore et al. (2005).

\section{A.2. Comparison of reconstructions in this paper with those of Gajewski (1988)}

The single-site reconstructions from the GLM ratio model shown in Fig. 1 can be compared to those reported for these sites in Gajewski (1988). Graphs of these comparisons are shown below. The Gajewski reconstruction is shown in green in each panel; the time series data come from NOAA/NCDC-Paleoclimatology/World Data Center for Paleoclimatology, at the following URL ftp://ftp.ncdc.noaa.gov/pub/data/paleo/ pollen/recons/liadata.txt.
These comparisons indicate that the original reconstructions by Gajewski, based on inverse model multiple regression of JJA temperature on Betula, Picea, Quercus and Poaceae (grass) pollen proportions (as reported in the original article, Table 2), are similar to those developed from the ratio model. This is especially true for the Ruby Lake and Little Pine Lake sites. The primary difference is that the 18th and 19th century values tend to be higher for the Gajewski reconstructions at Dark Lake (especially) and Ruby Lake, to the extent that they are often outside the $99 \%$ reconstruction probability envelopes of the ratio model outcomes. The 19th century Gajewski 
reconstructions for Little Pine Lake show a similar characteristic to a lesser degree, as do the 20th century reconstructions for Dark and Ruby Lakes. Reconstruction of the 1961-1990 summer temperature climatology in the three-lakes area also tends to be high at each of the lakes.

\section{References}

Adam, D.P., West, G.J., 1983. Temperature and precipitation estimates through the last glacial cycle from Clear Lake, California, pollen data. Science 219, 168-170.

Bartlein, P.J., Harrison, S.P., Brewer, S., Connor, S., Davis, B.A.S., Gajewski, K., Guiot, J., HarrisonPrentice, T.I., Henderson, A. Peyron, O., Prentice, I.C. Scholze, M., Seppa, H., Shuman, B, Sugita, S., Thompson, R.S., Viau, A.E., Williams, J., Wu, H., 2010. Pollen-based continental climate reconstructions at 6 and $21 \mathrm{ka}$ a global synthesis. Climate Dynamics. doi:10.1007/s00382-010-0904-1 Published online, 30 September.

Booth, R.K., Notaro, M., Jackson, S.T., Kutzbach, J.T., 2006. Widespread drought episodes in the western Great Lakes region during the past 2000 years: geological extent and potential mechanisms. Earth and Planetary Science Letters 242, 415-427.

Brohan, P., Kennedy, J.J., Harris, I., Tett, S.F.B., Jones, P.D., 2006. Uncertainty estimates in regional and global observed temperature changes: a new dataset from 1850 . Journal of Geophysical Research 111, D12106. doi:10.1029/2005JD006548.

Cook, E.R., Woodhouse, C.A., Eakin, C.M., Meko, D.M., Stahle, D.W., 2004. Long-term aridity changes in the western United States. Science 306, 1015-1018.

Cook, E.R., Seager, R., Cane, M.A., Stahle, D.W., 2007. North American drought: reconstructions, causes, and consequences. Earth Science Reviews 81, 93-134.

Dean, J.S., 1994. The medieval warm period on the Southern Colorado Plateau. Climate Change 26, 225-241.

Diaz, H.F., Andrews, J.T., 1982. Analysis of the spatial pattern of July temperature departures (1943-1972) over Canada and estimates of the $700 \mathrm{mb}$ midsummer circulation during the middle and late Holocene. Journal of Climatology 2, 251-265.

Fereday, D.R., Knight, J.R., Scaife, A.A., Folland, C.K., 2008. Cluster analysis of North AtlanticEuropean circulation types and links with tropical Pacific sea surface temperatures. Journal of Climate 21, 3607-3703. doi:10.1175/2007JCLI1875.1.

Gajewski, K., 1988. Late-Holocene climates of eastern North America estimated from pollen data. Quaternary Research 29, 255-262.

Gajewski, K., Winkler, M., Swain, A.M., 1985. Vegetation and fire history from three lakes with varved sediments in northwestern Wisconsin (U.S.A.). Reviews of Paleobotany and Palynology 44, 277-292.

Gelman, A., Carlin, J.B., Stern, H.S., Rubin, D.B., 2004. Bayesian Data Analysis, 2nd ed. Chapman \& Hall/CRC Press, Boca Raton, FL, USA

Graham, N.G., Hughes, M.K., 2007. Reconstructing the mediaeval low stands at Mono Lake, Sierra Nevada, California. The Holocene 17, 1197-1210.

Graham, N.G., Hughes, M.K., Ammann, C.M., Cobb, K.M., Hoerling, M.P., Xu, T., Kennett, D.J., Kennett, J.P., Rein, B., Stott, L., Wigand, P.E., 2007. Tropical Pacific mid-latitude teleconnections in medieval times. Climatic Change 83, 241-285.

Graham, N.E.C.M., Ammann, D., Fleitmann, K.M., Cobb, J. Luterbacher, 2010. Support for global climate reorganization during the "Medieval Climate Anomaly". Climate Dynamics. doi:10.1007/s00382-010-0914-z.

Graumlich, L.J., 1993. A 1000-year record of temperature and precipitation in the Sierra Nevada. Quaternary Research 39, 249-255.

Hadfield, J., 2010. MCMC methods for Multi-response Generalised Linear Mixed Models: The MCMCglmm R 47 Package. Journal of Statistical Software 33 (2), 1-22.

Hughes, M.K., Brown, P.M., 1992. Drought frequency in central California since 101 BC recorded in giant sequoia tree rings. Climate Dynamics 6, 161-167.
Kistler, R., Kalnay, E., Collins, W., Saha, S., White, G., Woollen, J., Chelliah, M., Ebisuzaki, W., Kanamitsu, M., van den Dool, H., Jenne, R., Fiorino, M., 2001. The NCEP/NCAR 50-year reanalysis: monthly means, $\mathrm{CD}-\mathrm{ROM}$ and documentation. Bulletin of the American Meteorological Society 82, 152-168.

La Marche Jr., V.C., 1974. Paleoclimatic inferences from long tree-ring records. Science $183,1043-1048$

Laird, K.R., Cumming, B.F., Wunsam, S., Rusak, J.A., Oglesby, R.J., Fritz, S.C., Leavitt, P.R. 2003. Lake sediments record large-scale shifts in moisture regimes across the northern prairies of North America during the past two millennia. Proceedings of the National Academy of Sciences 100, 2483-2488.

Mason, J.A., Swinehart, J.B., Goble, R.J., Loope, D.B., 2004. Late-Holocene dune activity linked to hydrological drought, Nebraska Sand Hills, USA. The Holocene 14, 209-217.

McCabe, M., Palecki, Betancourt, J.L., 2004. Pacific and Atlantic Ocean influences on multidecadal drought frequency in the United States. Proceedings of the National Academy of Sciences 101, 4136-4141.

Ohlwein, C., Wahl, E., Review of probabilistic pollen-climate transfer methods. Quat. Sci. Rev. (accepted for publication).

Salzer, M.W., Kipfmueller, K.F., 2005. Reconstructed temperature and precipitation on a millennial timescale from tree-rings in the southern Colorado Plateau, U.S.A. Climate Change 70, 465-487.

Schölzel, C., Hense, A., 2011. Probabilistic assessment of regional climate change in Southwest Germany by ensemble dressing. Climate Dynamics 36, 2003-2014.

Seager, R., Graham, N.E., Herweijer, C., Gordon, A.L., Kushnir, Y., Cook, E.R., 2007. Blueprints for Medieval hydroclimate. Quaternary Science Reviews 26, 2322-2336.

Shinker, J.J., Bartlein, P.J., Shuman, B., 2006. Synoptic and dynamic climate controls of North American mid-continental aridity. The Quarterly Review 25, 1401-1417.

Shuman, B., Henderson, A.K., Plank, C., Stefanova, I., Ziegler, S.S., 2009. Woodland-toforest transition during prolonged drought in Minnesota after ca. AD 1300. Ecology 90, 2792-2807.

Stahle, D.W., Fye, F.K., Cook, E.R., Griffin, R.D., 2007. Tree-ring reconstructed megadroughts over North America since A.D. 1300. Climate Change 83, 133-149.

Stine, S., 1994. Extreme and persistent drought in California and Patagonia during mediaeval time. Nature 269, 546-549.

Trouet, V., Esper, J., Graham, N.E., Baker, A., Scourse, J.D., Frank, D.C., 2009. Persistent positive North Atlantic Oscillation mode dominated the Medieval Climate Anomaly. Science $324,78-80$

Viau, A.E., Gajewski, K., 2009. Reconstructing millennial-scale, regional paleoclimates of boreal Canada during the Holocene. Journal of Climate 22, 316-330. doi:10.1175/2008JCLI2342.1.

Wahl, E., Schoelzel, C., Williams, J., Tigrek, S., 2010. Comment: The use and value of Bayesian hierarchical modelling for paleoclimate reconstruction: including a new pollen-climate data model. Journal of the American Statistical Association 105 (491), 900-905. doi:10.1198/jasa.2010.ap10295 (plus supplemental material).

Webb III, T., 1986. Is vegetation in equilibrium with climate? How to interpret LateQuaternary pollen data. Vegetation 67 (2), 75-91.

Whitmore, J., Gajewski, K., Sawada, M., Williams, J.W., Shuman, B., Bartlein, P.J., Minckley, T. Viau, A.E., Webb III, T., Shafer, S., Anderson, P., Brubaker, L., 2005. Modern pollen data from North American and Greenland for multi-scale paleoenvironmental applications. Quaternary Science Reviews 24, 1828-1848.

Williams, J., Post, D., Cwynar, L, Lotter, A. Levesque, A, 2002. Rapid and widespread vegetation responses to past climate change in the North Atlantic region. Geology 30, 971-974. 